\title{
Preparation of Pure Plasmid or Cosmid DNA Using Single-Strand Affinity Matrix and Gel- Filtration Spin Columns
}

\author{
Thang T. Pham, Sangeeta Chillapagari and Arturo R. Suarez \\ CLONTECH Laboratories, Inc., Palo Alto, CA, USA
}

BioTechniques 20:492-497 (March 1996)

\begin{abstract}
A rapid method has been developed for ultrapure plasmid or cosmid DNA isolation from ten-mL to several hundred-mL cultures of Escherichia coli (midi to maxi prep). A cleared lysate is prepared by alkaline lysis, followed by a quick alcohol precipitation step. Denatured bacterial DNA and RNA having at least 20 nucleotides of single-stranded regions are removed from the supercoiled plasmid by binding strongly to the single-strand affinity matrix (SSAM $\left.{ }^{T M}\right)$. Plasmid DNA is then effectively purified on a gel-filtration spin column to remove SSAM, proteins, small RNA and salts. This method produces consistent yields of high-quality plasmids that are suitable for use in many molecular biology applications. In addition, recombinant cosmids of approximately $46 \mathrm{~kb}$ can be purified intact, free of chromosomal DNA.
\end{abstract}

\section{INTRODUCTION}

Many demanding molecular biology applications depend on high-quality plasmid DNA purified with high yields. Current plasmid preparation procedures are modifications of either the alkaline lysis method of Birnboim and Doly (3) or the boiling preparation of Holmes and Quigley (4). The first step of the purification process is usually to separate genomic DNA and cellular debris away from plasmid. Subsequent manipulations are necessary to purify plasmids from other undesirable contaminants, especially RNA and proteins. There are two popular methods for secondary purification. The first is the CsCl gradient ultracentrifugation method (8), which takes $15-48 \mathrm{~h}$ and requires expensive equipment. The second is based upon plasmid binding to solid supports, either an anionexchange matrix (7) or a silica-based resin in the presence of a chaotrope $(2,5,6)$. High-resolution, anion-exchange resins usually produce highly purified plasmid DNA, which has to be precipitated and resuspended in low-salt buffer after column purification. Silica-based plasmid purification systems usually produce plasmids of intermediate quality and inconsistent yield. These systems cannot be used to purify plasmid from sheared or denatured chromosomal DNA, which can be similar in size as compared to plasmid DNA (7). Both systems rely on multiple washing steps to remove contaminants.

In this paper, we demonstrate a system using the singlestrand affinity matrix (SSAM ${ }^{\mathrm{TM}}$ ) to remove denatured chromosomal DNA and RNA, followed by a gel-filtration spin column to produce high-quality supercoiled plasmid DNA. The simple procedure allows several plasmids, from a few $\mathrm{kb}$ to cosmid size (ca. $46 \mathrm{~kb}$ ), to be prepared simultaneously. The DNA yield is typically $2-5 \mu \mathrm{g}$ of DNA per $\mathrm{mL}$ of $\mathrm{LB}$ culture, which compares favorably to existing plasmid purification methods. The purified plasmids are suitable for many applications, such as restriction digestion, cloning, sequencing, polymerase chain reaction (PCR), probe synthesis and cell transfection.

\section{MATERIALS AND METHODS}

\section{Plasmid Purification System}

The CLONprep ${ }^{\mathrm{TM}}$ Plasmid Purification System from CLONTECH Laboratories (Palo Alto, CA, USA) provides buffers for a modified alkaline lysis, SSAM suspension for removal of denatured bacterial DNA and RNA, and CHROMA SPIN ${ }^{\mathrm{TM}}$ columns of different volume sizes for removal of proteins, degraded nucleic acids and small molecular weight molecules.

\section{Crude Extraction and DNA Purification}

Escherichia coli strains (DH5 $\alpha$ and HB101) containing plasmid vectors (pUC19 - $2.7 \mathrm{~kb}$, pDIRECT - $3.0 \mathrm{~kb}$, pSEAP $-5.8 \mathrm{~kb}$ and $\mathrm{pA} / \mathrm{T}-2-3.0 \mathrm{~kb}$ ) or a cosmid (pWE15 plus 38-kb insert) from CLONTECH were cultured at $37^{\circ} \mathrm{C}$ overnight in 25 -mL (midi) or 100-mL (maxi) LB media. Cells were pelleted by centrifugation for $15 \mathrm{~min}$ at $7000 \times \mathrm{g}$ in a Beckman JA20 rotor and centrifuge (Beckman Instruments, Fullerton, CA, USA). An outline of the plasmid DNA isolation is shown in Figure 1; the step-by-step procedure is described in the 
manufacturer's protocol. Cells were resuspended in $25 \mathrm{mM}$ Tris- $\mathrm{HCl}$ (pH 8.0), $10 \mathrm{mM}$ EDTA and $100 \mu \mathrm{g} / \mathrm{mL}$ RNase A (buffer 1) and lysed with an equal volume of $0.2 \mathrm{M} \mathrm{NaOH}$, $1 \%$ sodium dodecyl sulfate (SDS) (buffer 2). The lysate was neutralized by the same volume of $3 \mathrm{M}$ potassium acetate (buffer 3) and centrifuged at $30000 \times \mathrm{g}$ for $30 \mathrm{~min}$ at $4^{\circ} \mathrm{C}$. Plasmid DNA in cleared lysate was precipitated with either 2 vol of ethanol or $0.8 \mathrm{vol}$ of isopropanol. The nucleic acid pellet was resuspended in $50 \mu \mathrm{L}$ or $250 \mu \mathrm{L}$ of TE buffer (10 $\mathrm{mM}$ Tris- $\mathrm{HCl}, \mathrm{pH} 8.0,1 \mathrm{mM}$ EDTA) for the $25-$ or $100-\mathrm{mL}$ culture, respectively. One-half volume of SSAM suspension was mixed with the resuspended DNA to allow the denatured DNA and RNA with single-stranded regions to bind to this matrix over a $10-\min$ period with frequent agitation. The entire mixture was then loaded onto a pre-centrifuged CHROMA SPIN+TE-400 Column; a regular-size column was used for the 25-mL culture (midi prep), and a large-capacity (LC) size was used for the 100-mL culture (maxi prep). After a 5min centrifugation at $700 \times g$, the purified plasmid or cosmid was in the collection tube and ready for use.

\section{DNA Analysis}

The concentration of purified DNA was determined by spectrophotometric measurement of $\mathrm{OD}_{260}$ and $\mathrm{OD}_{280}$. A $1 \%$ agarose gel prepared in $0.5 \times$ TBE buffer $(45 \mathrm{mM}$ Trisborate, $1 \mathrm{mM}$ EDTA, $\mathrm{pH} 8.0$ ) containing ethidium bromide (EtdBr) was used in a GNA-200 mini-submarine gel electrophoresis system (Pharmacia Biotech, Piscataway, NJ, USA) to analyze plasmid DNA quality. A $0.5 \%$ agarose gel containing EtdBr was used for electrophoresis of cosmid DNA.

\section{Restriction Enzyme Digestion}

One microgram of purified plasmid was digested with HindIII or HpaII (New England Biolabs, Beverly, MA, USA) in a $20-\mu \mathrm{L}$ reaction volume for $1 \mathrm{~h}$ at $37^{\circ} \mathrm{C}$ using buffers supplied by the manufacturer. Digested DNA was electrophoresed in an agarose/EtdBr gel as described above.

\footnotetext{
E. coli pellet I

Alkaline Iysis (50 $\mathrm{min})$

Alcohol precipitation

(40 $\mathrm{min})$

I

SSAM treatment

(5-10 $\mathrm{min})$

I.

CHROMA SPIN+TE-400 Column (5 min)

I

Purified plasmid or cosmid DNA

Total time: $\sim 110 \mathrm{~min}$

Figure 1. Schematic representation of plasmid isolation using SSAM and a CHROMA SPIN+TE-400 Column.
} 


\section{DNA Sequencing}

Purified plasmids were used directly for standard or cycle sequencing using either non-isotopic or radioactive labeling. Fluorescent cycle sequencing of $1 \mu \mathrm{g}$ of pDIRECT was performed using the Applied Biosystems Taq DyeDeoxy ${ }^{\mathrm{TM}}$ Terminator Kit (Perkin-Elmer/Applied Biosystems Division [PE/ABI], Foster City, CA, USA) (1). The thermal cycling profile was $98^{\circ} \mathrm{C}$ for $2 \mathrm{~min}$, followed by 30 cycles of $96^{\circ} \mathrm{C}$ for $20 \mathrm{~s}, 44^{\circ} \mathrm{C}$ for $10 \mathrm{~s}$ and $60^{\circ} \mathrm{C}$ for $4 \mathrm{~min}$. Sequencing reactions were chromatographed on a Model 373A DNA Analysis System $(\mathrm{PE} / \mathrm{ABI})$ and analyzed under conditions recommended by the manufacturer. Radioactive sequencing of purified plasmid was performed using the $\Delta T$ th DNA Polymerase Sequencing Kit (CLONTECH).

\section{RESULTS AND DISCUSSION}

Our goal was to develop a versatile plasmid preparation system that could be used to purify plasmids of various sizes (up to $50 \mathrm{~kb}$ ) and copy numbers (from 1-700 copies per cell), as well as from several bacterial hosts. To this end, we combined SSAM and CHROMA SPIN+TE-400 Columns in a simple purification scheme. Supercoiled pUC19 plasmid or cosmid DNA was isolated from bacterial cell pellets by a modified alkaline lysis method (3). The majority of bacterial genomic DNA was removed after the addition of the high-salt buffer (buffer 3) and centrifugation; however, some sheared chromosomal DNA was not effectively removed from the cleared lysate. After alcohol precipitation and resuspension of the DNA, SSAM was used to selectively bind the denatured bacterial DNA and RNA having at least 20 nucleotides of sin-

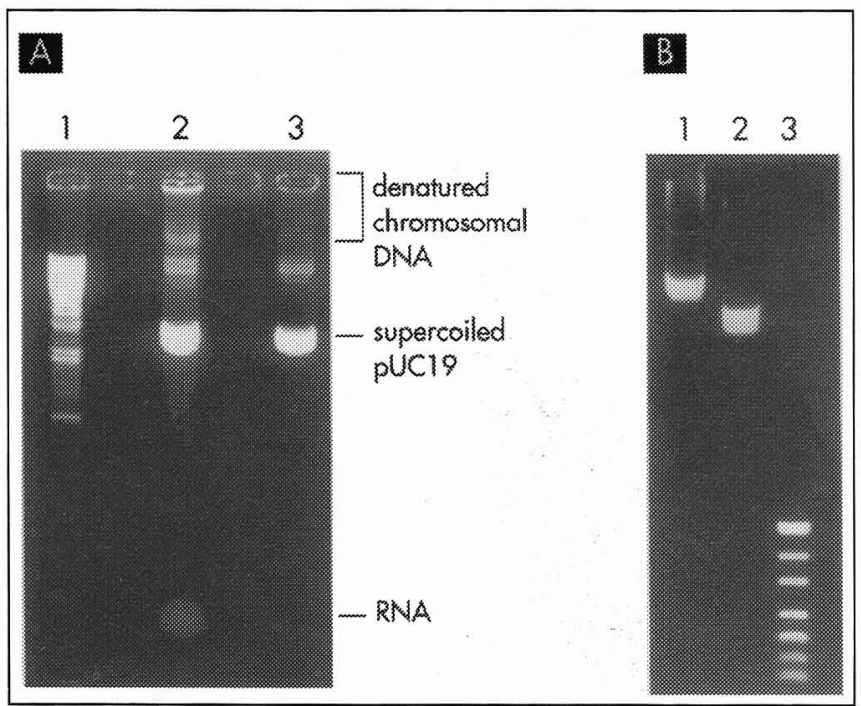

Figure 2. Preparation of pUC19 plasmid from $E$. coli using SSAM and a CHROMA SPIN+TE-400 LC Column. Bacterial pellet from a $100-\mathrm{mL}$ overnight LB culture was used for pUC19 isolation by the modified alkaline lysis method. The plasmid was quickly purified using SSAM to remove denatured chromosomal DNA and RNA, and a CHROMA SPIN+TE-400 LC Column to remove salts, proteins and all small molecules. (A) Samples of pUC19, before and after SSAM/CHROMA SPIN column purification, were electrophoresed on a $1 \%$ agarose/EtdBr gel. Lane 1, lambda/BstEII DNA size markers. Lane 2, pUC19 (2.7 kb) after the modified alkaline lysis. Lane 3, pUC19 after SSAM/CHROMA SPIN column purification $\left(A_{260} / A_{280}=1.9\right)$ (B) Samples of purified pUC19, before and after restriction enzyme digestion, were electrophoresed on a $2 \%$ agarose/EtdBr gel. Lane 1, supercoiled, purified pUC19. Lane 2, purified pUC19, digested with HindIII. Lane 3, purified pUC19, digested with HpaII. gle-stranded regions; supercoiled double-stranded plasmid did not bind. The gel-filtration CHROMA SPIN+TE-400 Column was subsequently used to remove SSAM and its bound nucleic acids and, at the same time, to retain any molecule smaller than the size of 300-bp DNA fragments, including protein complexes smaller than $5000 \mathrm{kDa}$. The purified cosmid and plasmids were substantially free of RNA, proteins and denatured chromosomal DNA. Samples of plasmid and cosmid before and after SSAM/CHROMA SPIN column purification were electrophoresed on the agarose gels, Figure 2 (Panel A) and Figure 3, respectively. The purified supercoiled DNA in sterile TE buffer was used directly as a sequencing template without any additional precipitation steps (discussed further below). The quality of purified plasmid was excellent; bacterial RNA and genomic DNA were quantitatively removed and plasmid DNA could be completely digested with restriction enzymes. pUC19 was digested with HindIII or HpaII as shown in Figure 2, lanes 2 and 3, Panel B. In addition, the large cosmid (ca. $46 \mathrm{~kb}$ ) showed very little shearing during this gentle and quick purification method.

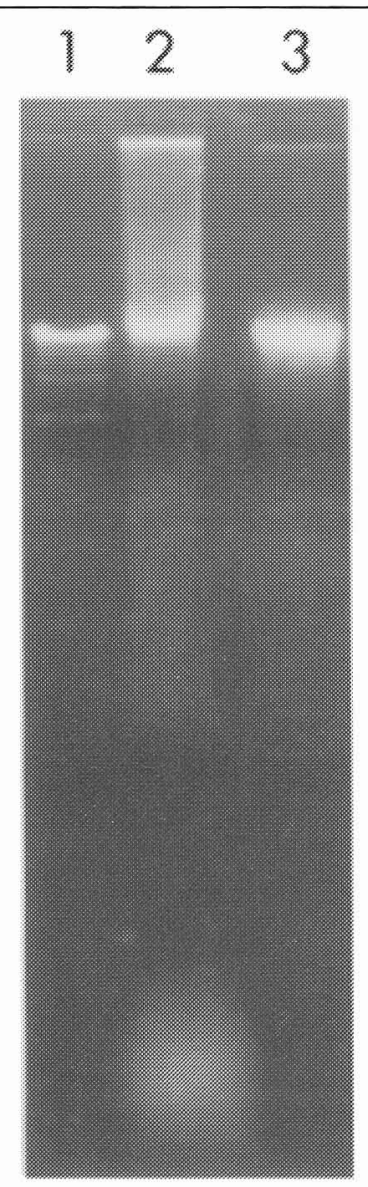

Figure 3. Preparation of cosmid "pWE15 + 38-kb insert" from $E$. coli using SSAM and a CHROMA SPIN+TE-400 LC Column. Bacterial pellet from a $100-\mathrm{mL}$ overnight $\mathrm{LB}$ culture was used for the isolation of a recombinant cosmid (ca. $46 \mathrm{~kb}$ ). After the modified alkaline lysis steps, the cosmid was quickly purified using SSAM to remove denatured chromosomal DNA and RNA and a CHROMA SPIN+TE-400 LC Column to remove salts, proteins and all other small molecules. Cosmid samples before and after SSAM/ CHROMA SPIN column purification were electrophoresed on a $0.4 \%$ agarose/EtdBr gel. Lane 1, high molecular weight DNA markers (48.5-8.3 kb) from Life Technologies (Gaithersburg, MD, USA). Lane 2, "pWE15 + 38-kb insert" after the modified alkaline lysis. Lane 3, "pWE15 + 38-kb insert" after SSAM/CHROMA SPIN column purification $\left(A_{260} / A_{280}=1.9\right)$. 
Table 1. Typical Yields and Purities of Plasmid and Cosmid DNA Isolated with the SSAM/CHROMA SPIN Column System

\begin{tabular}{|c|c|c|c|c|}
\hline $\begin{array}{l}\text { Plasmid } \\
\text { Type }\end{array}$ & $\begin{array}{c}\text { Vol. of } \\
\text { Culture }\end{array}$ & $\begin{array}{l}\text { Purification } \\
\text { Method }\end{array}$ & $\begin{array}{l}\text { Plasmid } \\
\text { Yield }\end{array}$ & $\begin{array}{l}A_{260} \\
A_{280}\end{array}$ \\
\hline pDIRECT (3 kb) & $25 \mathrm{~mL}$ & SSAM-CS-400 & $101 \mu \mathrm{g}$ & 1.8 \\
\hline pDIRECTb & $100 \mathrm{~mL}$ & SSAM/CS-400LC & $250 \mu \mathrm{g}$ & 2.0 \\
\hline pUC19 (2.7 kb) & $100 \mathrm{~mL}$ & SSAM/CS-400LC & $330 \mu \mathrm{g}$ & 1.9 \\
\hline Cosmidc (ca. $46 \mathrm{~kb})$ & $25 \mathrm{~mL}$ & SSAM/CS-400 & $30 \mu \mathrm{g}$ & 1.9 \\
\hline Cosmid (ca. 46 kb) & $100 \mathrm{~mL}$ & SSAM/CS-400LC & $117 \mu \mathrm{g}$ & 1.9 \\
\hline pSEAP (5.8 kb) & $25 \mathrm{~mL}$ & SSAM/CS-400 & $130 \mu \mathrm{g}$ & 1.8 \\
\hline pT/A2 (3 kb) & $100 \mathrm{~mL}$ & SSAM/CS-400LC & $360 \mu \mathrm{g}$ & 1.8 \\
\hline \multicolumn{5}{|c|}{ 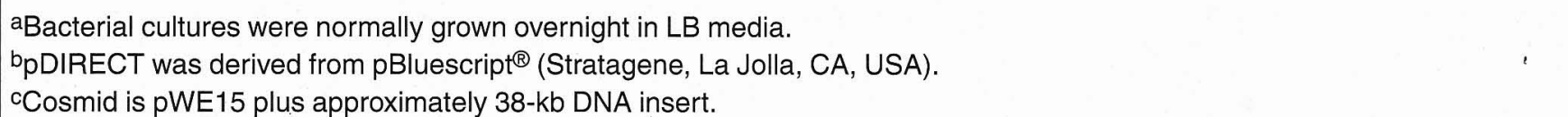 } \\
\hline
\end{tabular}

The yields of plasmid and cosmid DNA were high since the gel-filtration matrix has very little retention of large DNA molecules. The gel-filtration matrix effectively captures high amounts of small molecules in its pores, while large plasmid molecules pass through the matrix. Purified plasmids are collected after a few minutes of centrifugation. The method does not have washing and elution steps; therefore, it is simple, with relatively few manipulations. We routinely obtained $2-5 \mu \mathrm{g}$ of high copy number plasmids per $\mathrm{mL}$ of culture (LB) as determined by optical density at $260 \mathrm{~nm}$. The absorbance ratio, $A_{260} / A_{280}$, is usually 1.8 or greater. A summary of data obtained from several plasmid preparations

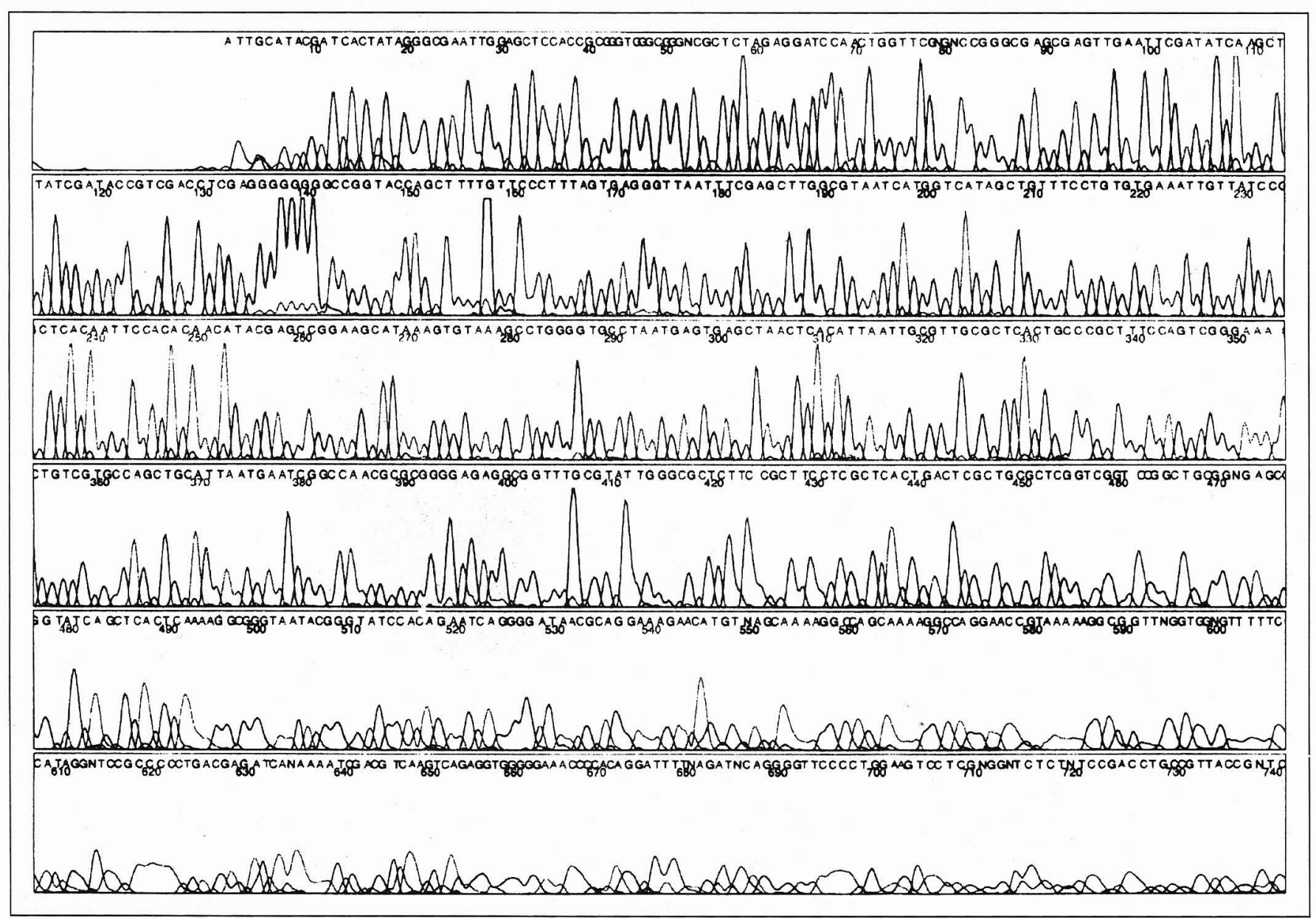

Figure 4. Fluorescent sequencing of supercoiled plasmid pDIRECT prepared by the SSAM/CHROMA SPIN column method. Purified pDIRECT was used as template for DNA sequencing with the Taq DyeDeoxy Terminator Kit. The cycle sequencing was performed according to the manufacturer's instructions (1) using the universal primer (24-mer). The reactions were chromatographed on a Model 373A DNA Analysis System with Version 2.0.1A software (PE/ABI). The DNA sequence could be clearly interpreted more than 500 bases from the primer. (Data was unedited.) 
is shown in Table 1.

Plasmid DNA purified by the SSAM/CHROMA SPIN column system is well suited for sequencing by either radioactive or fluorescent labeling methods. Plasmid template free of chromosomal DNA, proteins and salts usually provides low background in sequencing ladders and fewer ambiguous bases. Plasmid pDIRECT $(3 \mathrm{~kb})$, whose sequence is known, was used as template for fluorescent sequencing with the Taq DyeDeoxy Terminator Kit. The DNA sequence more than 500 bases from the primer could be clearly read when the reactions were chromatographed on the Model 373A sequencer (PE/ABI) (Figure 4). The error rate was very low $(<2 \%)$ for the first 500 bases. Several plasmids, purified by the SSAM/CHROMA SPIN column method, have also been used for radioactively labeled DNA sequencing, in vitro transcription, cell transfection and cloning (results are not shown). Although RNase A was added to buffer 1, the purified plasmid was free of detectable RNase A activity.

The SSAM/CHROMA SPIN column purification method is highly reproducible and quick to perform (takes $<2 \mathrm{~h}$ ). Because it requires less hands-on manipulation, this method is very convenient for the simultaneous preparation of several plasmids at midi and maxi scale. The procedure can also be scaled up to produce milligram amounts of plasmid by using several large-capacity CHROMA SPIN-400 LC Columns side-by-side in the same centrifuge. Therefore, this system is a very simple and reliable method for purification of highquality plasmid and cosmid DNA.

\section{ACKNOWLEDGMENTS}

We are grateful to Drs. Paul Siebert, Ying Luo, Li Zhu and Kristen Mayo and Ms. Carol Lou for careful reading of the manuscript and their valuable comments. We thank Theresa Provost for preparation of the figures and technical supports.

\section{REFERENCES}

1.Applied Biosystems. 1993. Quick Reference Guide. 373 DNA Sequencing System. Foster City, CA.

2.Bio 101, Inc. 1989. Geneclean. Instructions for uses of the Geneclean kit. La Jolla, CA.

3.Birnboim, H.C. and J. Doly. 1979. A rapid alkaline extraction procedure for screening recombinant plasmid DNA. Nucleic Acids Res. 7:15131523.

4.Holmes, D.S. and M. Quigley. 1981. A rapid boiling method for the preparation of bacterial plasmid. Anal. Biochem. 114:193-197.

5.Marko, M.A., R. Chipperfield and H.C. Birnboim. 1982. Procedure for the large scale isolation of highly purified plasmid DNA using akaline extraction binding to glass powder. Anal. Biochem. 121:382-387.

6.Promega Corporation. Wizard ${ }^{\mathrm{TM}}$ Maxipreps DNA Purification System Technical Bulletin, TB\#139. Madison, WI.

7.Qiagen, Inc. 1992. QIAGEN Plasmid Handbook for Plasmid Midi \& Maxi kit. Chatsworth, CA.

8.Sambrook, J., E.F. Fritsch and T. Maniatis. 1989. Molecular Cloning: A Laboratory Manual, 2nd ed. Cold Spring Harbor Laboratory Press, Cold Spring Harbor, NY.

Address correspondence to Thang T. Pham, CLONTECH Laboratories, Inc., 4030 Fabian Way, Palo Alto, CA 94303, USA. 